\title{
PÓS-MODERNIDADE E SOBERANIA ESTATAL: NOVOS PARADIGMAS E NOVOS SUJEITOS
}

Angela Limongi Alvarenga Alves ${ }^{1}$

Resumo: Segundo a tradicional concepção jurídica da soberania construída na modernidade, o Estado detém a exclusividade na produção do direito dentro de seu território. Na pósmodernidade, porém, a formulação do direito é permeada por múltiplos sujeitos, para além do Estado, provenientes de um corpo social bastante complexo e heterogêneo. A partir da análise do conceito de soberania estatal, procura-se demonstrar que a exclusividade normativa do Estado não persiste na atualidade e que a soberania atual é composta por novos paradigmas e novos sujeitos provenientes da sociedade civil.

Palavras-chave: Estado; Soberania estatal; Modernidade; Pós-modernidade; Novos sujeitos.

\section{POSTMODERNITY AND STATE SOVEREIGNTY: NEW PARADIGMS AND NEW SUBJECTS}

Abstract: According to the traditional legal concept of sovereignty built in the modernity, the State has the exclusive right to produce the law within its territory. In the postmodernity, however, the formulation of law is permeated by multiple subjects, beyond the State, coming from a very complex and heterogeneous social body. From the analysis of the concept of state sovereignty, it's tried to demonstrate that the normative exclusivity of the State doesn't persist in the present days and that the current sovereignty is composed of new paradigms and new subjects from civil society.

Key-words: State; State sovereignty; Modernity; Postmodernity; New subjects.

\section{Introdução}

O presente artigo analisa a soberania na pós-modernidade sob a perspectiva da Teoria do Estado, que, em grande medida, permanece entrecortada por postulados construídos na

\footnotetext{
${ }^{1}$ Doutora em Direito pela Universidade de São Paulo - USP (Brasil) e Pós-doutoranda na mesma instituição. Visiting Research Student na Universidade de Durham (Reino Unido). E-mail: angelalimongi@usp.br.
} 
modernidade. Atualmente, porém, tanto a disciplina quanto seus fundamentos passam por profundas transformações, de vez que se encontram permeados por estudos que buscam a transcendência desse modelo de pensamento, que por sua vez envolve a multiplicidade de conhecimento e de informação na sociedade hodierna, fenômeno que se percebe no século XX e se intensifica no século XXI. A saída de modelos econômicos, sociais e culturais estáticos em seus modelos primevos para formas híbridas é um dos paradigmas da modernidade que se busca deslocar em favor de uma preleção nova.

A terminologia "pós-modernidade" é, entretanto, bastante questionada por diversos teóricos. ${ }^{2}$ Todos, no entanto, buscam designar uma nova formatação na contemporaneidade, diferente daquela tradicional da modernidade inaugurada após a Revolução Francesa, que tinha no Estado sua principal promessa de segurança. ${ }^{3}$

Em que pesem as críticas e as construções teóricas provenientes da sociologia do direito, opta-se no presente trabalho pela terminologia "pós-modernidade", como descritiva de um fenômeno que altera a concepção tradicional de modernidade, e, sobretudo, como superação ao positivismo na contemporaneidade, marcada pela intensificação do risco e da insegurança, tornando tênue a demarcação entre Estado e sociedade e porosas as suas relações, alterando de forma indelével o direito e a soberania.

Nesse sentido, é importante estabelecer um contraponto entre a pós-modernidade e a globalização. A globalização ${ }^{4}$ não é um fenômeno novo. Compreendida em sentido amplo,

\footnotetext{
2 Dentre eles, Niklas Luhmann (1992), que prefere falar em "diferenciação funcional”, Anthony Giddens (2002), em "modernidade reflexiva", Ulrich Beck (2010) prefere falar em "sociedade do risco" como modo de vida "pósindustrial", Zygmunt Bauman (2000), em "modernidade líquida", Jürgen Habermas (2001), em "modernidade tardia", "madura" ou ainda "pós-modernidade", dentre outros. Esse rol de teóricos é exemplificativo.

${ }^{3}$ Essa promessa de segurança e o Estado, enquanto projeto civilizacional, porém, não se cumpriram. No século $\mathrm{XX}$, com as grandes guerras, o modelo ideal de Estado é questionado enquanto projeto civilizacional, já que o "projeto homem" não se materializa diante dos grandes massacres, genocídios e holocausto que marcaram os conflitos. Em razão disso, há o entendimento de que a pós-modernidade simplesmente não existe porque a modernidade ainda estaria sendo desenhada e, portanto, ainda estaria vigente.

${ }^{4} \mathrm{O}$ termo "globalização" tem caráter polissêmico, e comumente é designado como um conceito impreciso - e por isso mesmo enganoso, conforme Eduardo Faria (2011, p. 17). E talvez esse seja o maior desafio para qualquer tentativa em traçar a diferenciação entre globalização e pós-modernidade. Talvez um ponto de diferenciação entre globalização e pós-modernidade (muito embora se reconheça ser tênue e pouco clara essa diferenciação, mesmo entre os teóricos) seja a prevalência da natureza econômico-comercial da globalização, que acaba por afetar múltiplas dimensões da realidade, enquanto que a pós-modernidade tem no sistema econômico apenas uma de suas facetas - a mais forte - mas não o único fundamento, como se vê em Eduardo Bittar (2009, p. 221): “A pósmodernidade, enquanto fenômeno econômico, afeta economias mundiais, através da globalização, estejam os países em desenvolvimento ou sejam desenvolvidos, sejam os países do capitalismo central ou periférico, sejam socialistas ou capitalistas. A pós-modernidade, enquanto fenômeno tecnológico-científico, atinge as comunidades
} 
começa com as migrações do homo sapiens, passa pelas conquistas dos antigos romanos, a expansão do cristianismo e do Islã, as grandes navegações da modernidade, a difusão dos ideais da Revolução Francesa, o neocolonialismo do século XVIII, ganhando especial impulso após a II Guerra Mundial (LEWANDOWSKI, 2004, p. 50) e ainda mais depois do término da Guerra Fria, configurando antes de tudo um fenômeno econômico. Corresponde a uma intensa circulação de bens, capitais e tecnologia através de fronteiras nacionais, com a consequente criação de um mercado mundial ${ }^{5}$ (LEWANDOWSKI, 2004, p. 50-51) que se intensificou a partir da década de 1990.

Por tudo isso, é possível afirmar que a globalização é um processo paradigmático, multidimensional, de natureza eminentemente econômico-comercial, que acaba por enfraquecer os Estados nacionais em razão da intensificação dos movimentos do comércio e da economia. Já a pós-modernidade, pressupõe novas formas de conceber o mundo e a vida por sistemas de pensamento, calcados na efemeridade, na diluição de certezas e paradigmas, na porosidade das relações e na compressão entre tempo e espaço. Nela, há, por certo, o impulso econômico (talvez o mais forte deles), mas não o preponderante. A globalização, apesar de ser um fenômeno multifacetado, constitui, assim, uma parte da pós-modernidade, que por sua vez compreende algo muito maior. Cuida-se de pensar que os termos "globalização" e "pósmodernidade" não são sinônimos, mas não são, com efeito, excludentes.

Dessa forma, a emergência de novos sujeitos a interferir no direito dos Estados, impõem a identificação de novos paradigmas para a noção de soberania estatal. As transformações sofridas pela soberania, no entanto, não foram capazes de resolver a conflituosidade existente entre a sua significação mesma e o seu conteúdo prático. A conclusão se confirma ante a identificação de forças centrífugas tais como grupos de pressão na sociedade civil, institucionalizada ou não, movimentos sociais e terceiro setor atuando como novos

científicas brasileiras, tornando-as importantes canais de distribuição de informações, de conscientização, de problematização, resultando em mudanças na produção, na comunicação, no desenvolvimento tecnológico, na projeção empresarial-econômica etc. A pós-modernidade enquanto fenômeno político, faz das economias nacionais instrumentos de um processo maior, de abrangência internacional, joguetes de interesses políticos maisque-nacionais, estando à frente destes debates líderes dos processos de integração (Alca, Nafta, OEA, OMC, MCE...)".

${ }^{5}$ Assevera Lewandowski (2004, p. 52) que, a rigor, a globalização constitui uma progressiva interdependência entre distintos sistemas econômicos, da qual só se deu conta após a quebra da bolsa de Nova Iorque, em 1929, que arrastou o mundo a uma profunda depressão econômica. 
sujeitos da ordem social e questionando a centralidade e a exclusividade do Estado na produção do direito.

Assim, o presente artigo analisa a reformulação da soberania diante das transformações plasmadas pela pós-modernidade, investigando a produção do direito proveniente de outros loci para além do Estado, especificamente os que residem na sociedade civil, buscando compreender o seu papel nas transformações engendradas na soberania contemporânea.

\section{Soberania estatal: conceito e significações possíveis}

A doutrina clássica da soberania foi elaborada ao longo de séculos por teóricos, clássicos da política, como Jean Bodin (em 1576), Thomas Hobbes (em 1651), John Locke (em 1689), Charles Montesquieu (em 1748), Jean-Jacques Rousseau (em 1762) e Emmanuel Sieyès (em 1789) que a concebem de diversas formas. ${ }^{6}$

Todas essas teorizações, ainda que não tenham como fundamento único a soberania estatal, mas variações como soberania popular, soberania da nação e soberania do povo são

\footnotetext{
${ }^{6}$ Jean Bodin (1986) entende a soberania como poder uno, indivisível e incontrastável de autogoverno do Estado, pertencente ao soberano, figura essa que se confundia com o próprio Estado. Thomas Hobbes (1984) entende que os direitos monárquicos de decisão suprema constituem a essência da soberania e da própria política, inobstante tenha ele posteriormente redesenhado a teoria anterior de forma a permitir a compreensão das manifestações de poder do Estado como produto de um sistema de cooperação juridicamente coordenada (RANIERI, 2013, p. 96). Charles Louis Montesquieu (2005) preocupa-se com os limites do poder, que por sua vez derivam de um problema político. A partir daí, identifica as limitações inerentes ao poder político em dados extrajurídicos como condicionantes da ordem jurídica (RANIERI, 2013, p. 99). Jean-Jacques Rousseau (2007) propõe a reflexão acerca da preservação da liberdade natural do ser humano e ao mesmo tempo da garantia de segurança e bem-estar em sociedade. Tal desiderato só se viabiliza com a conformação ao contrato social, por meio do qual prevalece a soberania da sociedade, a soberania política da vontade coletiva: o elemento volitivo consubstanciado em povo e a criação da soberania popular. Emmanuel Joseph de Sieyès (1988), nos idos do século XVIII, acerca do poder constituinte, expressa a ideia de que a nação é preexistente ao próprio Estado e sua vontade é sempre legal, porque representativa da própria lei, só existindo acima dela o direito natural. Para as leis positivas, basta o exame das leis constitucionais que regulam a organização e as funções do poder legislativo. As leis são fundamentais, não por serem obra de um poder constituído, mas de um poder constituinte, que não se encontra subjugado a nenhum outro (BULOS, 2009, p. 131). A soberania, pertence à nação em generalidade, essa no sentido de não se limitar em exercício a nenhuma parcela de indivíduos, pois que, pertencente à comunidade inteira. John Locke, por sua vez, propõe a soberania do povo através do parlamento. Para ele, o Estado não é um fim em si mesmo, mas instrumento da missão confiada pelo povo aos governantes (RANIERI, 2013, p. 98), o que ia ao encontro dos ideários dos revolucionários franceses e americanos e que se aspergiram mundo afora. Tendo em vista essas concepções, as teses clássicas são normalmente caracterizadas pela doutrina como as legislativas ou as executivas (MIRANDA, 2015, p. 126). As legislativas encontram a essência da soberania na emissão da lei (assim, Bodin, Locke e Rousseau) e as executivas, no momento da execução ou coerção (assim, Hobbes). E há aqueles que ligam a soberania ao poder de emitir moeda, ao de lançar tributos, ao de punir e ao de recrutar tropas. Assim como quem sustente que soberano é quem decreta o estado de exceção (assim a doutrina jurídica de Carl Schmitt). Essas teses não têm a ver propriamente com as condições de existência do Estado, mas ligam-se ao domínio e às funções do Estado (MIRANDA, 2015, p. 126), portanto a um conteúdo mais político e abstrato.
}

CONPEDI LAW REVIEW | Braga - Portugal | v. 3 | n. 2 | p. 262 - 283 | JUL/DEZ. 2017 
relevantes porque foi a partir delas que a concepção de soberania do Estado se desenvolveu e se consolidou (PAUPÉRIO, 1958, p. 39).

Assim, lançadas as bases teóricas da soberania, diversos estudiosos se ativeram em aprofundá-la, cuidando principalmente de suas implicações e desdobramentos. Na Alemanha, pesquisas acuradas no campo das filosofias política e jurídica, germinaram a ideia de soberania do Estado. Em estudo absolutamente inovador para a época, Friedrich Wilhelm Joseph Von Schelling (1775-1854) passa a conceituar o Estado como um organismo determinado pelo seu fim e caracterizado pela formação mecânica e pela adaptação às necessidades objetivas que lhe dão a razão de ser. Paralelamente, Hegel (1770-1831) elabora uma ideia de Estado, segundo a qual o Estado constitui uma realidade moral. A soberania estatal, decorre, portanto, da unidade do Estado, como ser com personalidade (PAUPÉRIO, 1958, p. 111).

Tais estudos abriram caminho para que a publicística alemã iniciada por Krause concebesse a ideia de Estado como ideal, ético, formado por um processo histórico e psicológico, defendendo a existência de uma personalidade, mais tarde consolidada no século XIX por Carl Friedrich Von Gerber, Otto Friedrich Von Gierke e Georg Jellinek como personalidade jurídica, firmando o entendimento da soberania calcada na figura do Estado, que se sedimenta na modernidade e chega até os presentes dias (PAUPÉRIO, 1958, p. 112-113).

A ideia de soberania do Estado se fundamenta na realidade jurídica com que o mesmo se reveste, enquanto pessoa jurídica. Como tal, adquire a capacidade de contrair direitos e obrigações e, portanto, de criar o seu direito.

Por essa razão, parte-se do conceito segundo o qual a soberania se entrelaça à ideia de personalidade jurídica do Estado, enquanto poder originário e exclusivo que tem o Estado de declarar e assegurar por meios próprios a positividade de seu direito e de resolver em última instância sobre a validade de todos os ordenamentos jurídicos internos (REALE, 2000, p. 157) - conceito esse que se fortaleceu e se consolidou na modernidade.

\section{Modernidade, direito e soberania}

A modernidade, em acorde com Anthony Giddens (1991, p.11), traduz o estilo, o costume de vida ou organização social que emergiu na Europa a partir do século XVII e que ulteriormente se tornou mais ou menos mundiais em sua influência. Eduardo Bittar (2009, p. 
35) assevera que a modernidade deve também ser compreendida como um conjunto de transformações culturais, sociais e econômicas, bem como políticas, que haveriam de se produzir, sustentadas por fortes ideais filosóficos, entre os séculos XVII e XIX, com vistas à consolidação de características tornadas como projeto-meta para a reconfiguração das relações humanas e sociais na Europa ocidental, algo que acabou por se universalizar.

A modernidade, enquanto projeto de ruptura para com as "trevas" representadas pelo medievo, tem a ordem como projeção da razão, já que a ordenação - o planejamento e execução da ordem - é essencialmente uma atividade racional, afinada com os princípios da ciência moderna e, de modo mais geral, com o espírito da modernidade (BAUMAN, 1999, p. 47). Eis o momento do nascimento das instituições modernas, como a ciência empírica, a burocracia de Estado e o ordenamento jurídico, permitindo afirmar, com clareza, que a principal tarefa da modernidade é a de criar ordem (BITTAR, 2009, p. 54).

E com a ordem, o cálculo, o exercício métrico da razão acaba por se impor como parte de um processo arquitetural de ordenação: dominação, projeção, organização, planejamento (BITTAR, 2009, p. 53-54) e segurança são desdobramentos da razão, postos sobre um ambiente de desordem e insegurança que precisava ser organizado.

Assim, o direito, a legalidade e o Estado desempenham um papel garantidor neste contexto da afirmação da ordem e da própria modernidade enquanto projeto político. É nesse sentido e contexto que a estabilização do projeto moderno reclama a lei escrita e codificada como projeto próprio para unificação dos direitos, e, mais, para a estratificação das relações sociais em conteúdos controláveis de realização do poder (ALVES, 2011, p. 30), de modo que a semântica da lei deixa de ser simplesmente a expressão de um direito neutro e textual para significar a expressão do poder de organização e controle (FOUCAULT, 1979, p. 101).

Os corolários do projeto moderno de direito podem ser sintetizados no constitucionalismo, na separação de poderes, nas declarações de direitos e na formulação geral de Estado de direito, condensadores da ideia de segurança inerente à modernidade. Dentro dessas perspectivas, é possível entrelaçar o fortalecimento da consciência social moderna e o estabelecimento de uma cultura jurídica, a positivista, favorável ao assentamento da modernidade. Há, portanto, um paralelo crescimento do direito, com um crescimento da ordem (que se torna parte da bandeira positivista) e do aparelhamento do Estado (BITTAR, 2009, p. 
67) - ponto fulcral para o fortalecimento da concepção da teoria da soberania estatal, bem como a ideia de exclusividade do Estado na produção do direito. A ordenação do direito e a estabilidade que ele promove através de sua positivação traçam um contexto favorável para a afirmação do projeto da modernidade: um direito seguro, estável, rígido e formal, posto pelo Estado, amalgamado pela soberania.

\section{Pós-modernidade, direito e soberania}

A racionalidade e a ordenação do projeto da modernidade, no entanto, acabaram abalados pelas consequências das grandes guerras mundiais do século $\mathrm{XX}$, descrito por Anthony Giddens (2002, p. 19) como o século da guerra, com um número de conflitos militares sérios envolvendo perdas substanciais de vidas, consideravelmente mais do que em qualquer um dos séculos precedentes.

Esse cenário convolou todo um processo de contestação de valores, um despontar de novas ideias, um renovar dos modos e práticas sociopolítico-jurídicas. O fortalecimento do conceito de soberania estatal que se deu na modernidade começa a ser questionado, diante da necessidade de construção de um arcabouço normativo protetivo das liberdades e dos direitos humanos.

Alguns dos debates sobre estas questões se concentram principalmente sobre transformações institucionais, particularmente as que sugerem que há um deslocamento de um sistema baseado na manufatura de bens materiais para outro, relacionado com a informação, a partir da segunda metade do século XX. Mais frequentemente, contudo, estas controvérsias enfocam também questões de filosofia e epistemologia (GIDDENS, 1991, p. 11-12), e por certo, afetam o direito.

O sistema jurídico sofre diretamente as consequências da pós-modernidade, pois se sabe não sê-lo um sistema autônomo, mas dependente e relacionado aos outros sistemas - social, cultural, econômico, político, dentre outros (CAMPILONGO, 2000, p. 115), o que resulta em desestruturação dos modos tradicionais de concebê-lo.

Em lugar das certezas modernas - ideia de verdade, ciência, ordem, regra, poder central, norma, código, capital, produção etc - um outro quadro se instaura, trazendo mudanças paradigmáticas plasmadas nas ideias de desordem, dissenso, desmantelamento, descompasso, 
desestruturação, contradição etc. A percepção dessas características na atualidade permitem afirmar que o direito tem se tornado cada vez mais complexo e variável, somando-se a esse contexto a ideia de fragilidade e de instabilidade pós-modernas (CASELLA, 2011, p. 1000).

Para além desse cenário, há que se destacar as teorias da pós-modernidade que a compreendem segundo um sentido de compressão da relação tempo e espaço e na necessidade de se produzir mais, com mais lucro e em espaço de tempo cada vez menor (HARVEY, 2008, p. 7) e quanto à intensificação das interações sociais fundadas na sociedade de consumo, já que as condições de vida boa só se consolidam com o consumo, não bastando apenas os ideais de vida digna segundo o marco keynesiano de Estado intervencionista presente na modernidade (saúde, educação, trabalho, segurança pública, previdência social etc), havendo, portanto, a fetichização do consumo: a felicidade, bem como a realização pessoal e profissional só são alcançadas pela via do consumo (LIPOVETSKY, 2005, p. 65).

E assim, o Estado não consegue mais dar respostas adequadas à sociedade, exceto aquelas favoráveis ao lucro, observados os interesses do mercado e o do consumo. Com isso, a regulação da economia passa a exigir novas concepções de políticas públicas e novos instrumentos normativos (FARIA, 2011, p. 51). Essa ideologia tem apontado para a redução do Estado ao Estado mínimo. O resultado é a desvinculação do Estado de suas funções controladoras, reguladoras e diretoras, levando-o a se render ao pluralismo jurídico e à substituição da tradicional rigidez hierárquica dos códigos e das leis, postulada pela modernidade, pela diversidade e flexibilidade normativas (FARIA, 2011, p. 52), além da abdicação do poder de regulação e na entrega de redes sociais de proteção e demais instituições de bem-estar coletivo à sociedade civil. Assim, ao lado do Estado e das forças de mercado a atacar a soberania, emergem novos sujeitos a reclamar por novos paradigmas do direito, e, portanto de soberania.

\section{Soberania estatal: novos paradigmas e novos sujeitos}

A pós-modernidade e as transformações por ela engendradas erodem o direito e o Estado, sobretudo o seu aparato de garantias: a permeabilidade do direito às incertezas, inflexões e fluidez da pós-modernidade, robustecida pela lógica mercadológica, a inconstância da lei da oferta e da procura para a precificação dos bens de consumo acaba sendo transferida para a esfera jurídica, em detrimento do sistema de direitos garantido pelo Estado. 
A redução do Estado ao Estado mínimo, a ultravalorização do mercado e todas as consequências provenientes do contexto pós-moderno, por certo, atingem também o Brasil. Esse processo, no entanto, relaciona-se à construção da ideia de cidadania brasileira.

A cidadania no Brasil, pensada com José Murilo de Carvalho (2002), constituiu-se segundo um processo que conferiu ao Estado o protagonismo no reconhecimento de direitos, construindo, outrossim, uma cidadania "de cima para baixo" : no primeiro plano, esteve o reconhecimento dos direitos sociais por um Estado deveras paternalista, através de robusta produção legislativa destinada a uma população pouco instruída e educada; e apenas em segundo plano esteve a preocupação com os direitos políticos e com a efetiva participação política cidadã.

Apesar disso, com a pós-modernidade verifica-se o ressurgimento da sociedade civil brasileira no cenário político e a assunção de um status ativo por ela ocupado, o que importa reconhecer que mesmo diante de uma possível retração do Estado (talvez indesejada, a depender da intensidade) floresce uma cidadania "de baixo para cima", com autonomia e consciência incipientes, mas ainda assim significativas. ${ }^{8}$

A emergência da sociedade civil brasileira na pós-modernidade se dá como recurso organizacional da vida coletiva sob a diretriz constitucional da liberdade de associação e fomento à participação democrática. Em um cenário em que a ultravalorização do mercado é uma realidade, a participação da sociedade civil emerge como resposta ao estrangulamento representando pela intensificação do processo de globalização, o qual constitui apenas uma

\footnotetext{
${ }^{7}$ Diferentemente do paradigmático estudo de Marshall (1963) que preconiza a evolução da cidadania segundo a evolução dos direitos conquistados: no primeiro plano, o elemento civil, que se revela nos direitos de liberdade (individuais), no segundo, o político, que se reveste no direito de participação no poder político e o elemento social, que se refere aos direitos econômicos, sociais e culturais. Nessa perspectiva, esses direitos constituem conquistas do cidadão em face do Estado, ou seja, contra ele e não uma concessão feita por ele, como aponta o estudo de Carvalho (2002), em relação à construção da cidadania brasileira.

${ }^{8}$ É importante pontuar que o florescimento da sociedade civil brasileira ganhou impulso a partir do chamado "Consenso de Washington", que preconizava a redução do Estado através da disciplina fiscal, abertura comercial, estímulo a investimentos financeiros, privatização de empresas públicas, desregulamentação e principalmente, a produção normativa por outros sujeitos, para além do Estado. Aponta Lewandowski (2004, p. 65-66) que o Consenso de Washington representou um poderoso veículo para a difusão do ideário neoliberal no mundo. Surgiu como um receituário para combater a crise econômica em que se debatiam os países latino-americanos nos anos 1980, caracterizada por elevadas taxas de inflação, déficits públicos crônicos, ineficiência governamental, obsolescência industrial e hermetismo de mercado.
} 
parte da pós-modernidade. Assim, a sociedade civil na pós-modernidade passa de receptora à produtora do direito.

\subsection{Sociedade civil}

Ensina Norberto Bobbio (2011, p. 35) que o termo "sociedade civil”" comporta diversos significados, tendo como pressuposto o elemento não-estatal, sendo necessário, por certo, delimitar a extensão do próprio Estado. Entretanto, é com esse teórico que se tem a conceituação acerca da sociedade civil, segundo a qual, numa primeira aproximação, pode-se afirmar que a sociedade civil é a instância em que surgem e se desenvolvem os conflitos econômicos, sociais, ideológicos e religiosos que as instituições estatais têm o dever de resolver ou através da mediação ou através da repressão. São sujeitos desses conflitos as classes sociais ou mais amplamente os grupos, os movimentos, as associações, as organizações de classe, os grupos de interesse, as associações de vários gêneros com fins sociais, e indiretamente políticos, os movimentos de emancipação de grupos étnicos, de defesa dos direitos civis, de libertação da mulher, os movimentos de jovens etc (BOBBIO, 2011, p. 36). Por essa razão, o estudo da sociedade civil e dos impactos da sua mobilização para o direito é de suma importância, e, sincreticamente, a compreensão do ambiente normativo em que ela atua.

\subsection{Movimentos sociais}

Boaventura de Sousa Santos (2005, p. 256) preleciona que os anos 1980 foram marcados pela temática dos novos sujeitos e dos novos movimentos sociais. ${ }^{9} \mathrm{Na}$ contemporaneidade, a temática dos movimentos sociais é retomada e ganha força, sobretudo, nos estudos pós-modernos. A tentativa de conceituar e contextualizar os movimentos sociais, no entanto, é extremamente dificultosa, pois não há consenso entre os teóricos. ${ }^{10}$

\footnotetext{
${ }^{9}$ Segundo Campilongo (2012, p. 18-30), diz-se "novos movimentos sociais" para designar a teoria dos novos movimentos sociais em contraposição às teorias anteriores sobre movimentos sociais, como teoria da ação coletiva (collective behavior) e teoria da mobilização de recursos (ressource mobilization and political process), ambas especialmente desenvolvidas nos Estados Unidos, com forte componente empírico-descritivo dos modos de organização, ação, estruturas e resultados. Os estudos sobre os novos movimentos sociais (new social movements) têm origem europeia e buscam explicações para as mudanças sociais de grande escala nas sociedades pósmodernas. E é sob essa perspectiva que os movimentos sociais serão analisados no presente trabalho.

${ }^{10}$ A literatura sobre o tema perpassa a ciência política, a psicologia social, a sociologia e é bastante vasta e pouco uniforme. Em razão disso, Michael McCann (2006, p. xiii) enfatiza que os movimentos sociais são definidos pelos estudiosos de diversas formas e em diversos contextos. A dificuldade conceitual dos movimentos sociais evidencia-se em razão do entrelaçamento para com a realidade histórica em que eles se inserem, composta por diversas variantes, complexidades e heterogeneidades (MELUCCI, 2001, p. 43). Nesse mesmo sentido, Götz
} 
Apesar disso, algumas características dos movimentos sociais podem ser destacadas: (i) são lastreados em conflitos que se relacionam à utilização de recursos escassos; (ii) não se limitam a reagir a panoramas econômicos desvantajosos; (iii) o reconhecimento de liberdade não necessariamente se faz acompanhar de seu efetivo gozo (os movimentos se insurgem contra a sociedade sem perceberem que dela fazem parte); (iv) atuam em sociedades complexas, ou seja, com múltiplas facetas da vida social; (v) a sociedade em que atuam está relacionada à variabilidade e assim, o passado não é mais inspiração para o presente; (vi) a sociedade em que atuam tem a complexidade como essência; (vii) funcionam como catalisadores da variabilidade social do ambiente complexo em que vivem; (viii) os conflitos de classes não explicam o desempenho e a atuação dos movimentos sociais na pós-modernidade; (ix) requerem liberdade e informalidade para o atendimentos de seus propósitos; (x) não são meros atores sociais ordinários (exemplo disso é a luta pelos direitos humanos), mas sujeitos de direito, o que permite perceber a coexistência e pertinência entre os movimentos sociais e o direito (CAMPILONGO, 2012, p. 23-31).

Assim, para compreender os movimentos sociais no contexto da pós-modernidade, bem como a sua interface com o direito, elege-se a teoria dos novos movimentos sociais ${ }^{11}$ como ponto de partida para as análises que se seguem.

Os teóricos dos novos movimentos sociais partem da construção de diagnóstico sobre as transformações da sociedade moderna para compreender o surgimento de novas formas de conflito, bem como as suas manifestações. Eles identificam a mudança de paradigmas da sociedade capitalista, dando passagem a outra organização estrutural, pós-moderna, como explicita Celso Fernandes Campilongo (2012, p. 28):

Se os conflitos anteriores tinham seu lugar em sociedade marcada por questões de crescimento econômico, redistribuição e seguridade social, características das democracias representativas de Bem-Estar na Europa Ocidental do pós-guerra, o

Ottmann (1995, p. 188) assinala a fluidez como uma das características mais marcantes dos movimentos sociais, passível de explicar a mutabilidade que um mesmo movimento pode apresentar, a depender do local e período histórico analisado.

${ }^{11} \mathrm{Na}$ Europa, no final dos anos 1960, a emergência de movimentos estudantis, que foram logo seguidos por outros movimentos como os feministas, pacifistas, ecológicos etc, desafiou o pensamento marxista tradicional à época, que via no movimento operário a expressão da contradição fundamental da sociedade capitalista moderna. Ao analisar os protestos que não estavam diretamente relacionados às condições de trabalho nas fábricas, alguns teóricos buscavam compreendê-los teoricamente, indicando que esses seriam "novos" movimentos, para diferenciá-los dos "velhos" movimentos trabalhistas e sindicais (CAMPILONGO, 2012, p. 27). 
declínio do consenso keynesiano daria lugar a preocupações com o 'território físico, com o espaço de ação ou mundo da vida, tal como o corpo, saúde e identidade sexual; a vizinhança, a cidade e o meio ambiente; identidade e tradição cultural, étnica, nacional e linguística; as condições físicas de vida e a sobrevivência da humanidade em geral' ou, em resumo, com questões diretamente relacionadas à vida privada.

Essas novas pautas dos movimentos sociais, excessivamente amplas e abrangentes, contribuíram para afastá-los da política institucional, bem como da organização tradicional de representação de demandas. Especificamente no contexto brasileiro, a diversidade de temáticas dos movimentos sociais se soma à herança do regime militar, aos resquícios de autoritarismo que levaram (e ainda levam) à rejeição por seguimentos dentro da própria sociedade civil ao embate direto para com o Estado, convolando a preferência desses movimentos pela informalidade.

Essa informalidade ${ }^{12}$, no entanto, não retira o potencial transformador desses movimentos, a afetar o direito. Os movimentos sociais não se limitam a apresentar demandas, através de manifestações, para os tomadores de decisão. Eles também expressam conflituosidades e discussões políticas, imprimindo esforços para o debate de diversas temáticas na arena pública, para além dos canais institucionalizados. Passam a alterar a produção do próprio direito, seja na produção normativa propriamente dita, seja conquanto a sua interpretação e aplicação.

Com a pós-modernidade, a sociedade civil passa a tematizar e a discutir demandas sociais junto à esfera pública diretamente, e não só: passa a atuar em canais não institucionais. Essas ações alteram a formulação da própria política, a ser visualizada como uma meta-política (DELLA PORTA, 2009, p. 26).

Os movimentos sociais informais, os movimentos autodenominados simplesmente “coletivos" (coletivos negros, feministas, pró-uso racional de água etc), as redes formadas pelas tecnologias de informação e comunicação (TICs), ${ }^{13}$ dentre outros buscam reconhecimento e

12 Apesar da "turn to culture" experienciada pelos movimentos sociais a partir dos anos 1980, a enfatizar a necessidade de apreensão de conceitos alternativos, como identidade, autonomia, reconhecimento de formas alternativas de propriedade dentre outros, há, no entanto, dificuldades de obtenção de visibilidade e reconhecimento de sua importância no tocante aos estudos jurídicos acerca da ação dos atores socioeconômicos e culturais na composição dos direitos delineados e conquistados (RAJAGOPAL, 2003, p. 246).

${ }^{13}$ As tecnologias de informação e comunicação (TICs) também interferem na participação política propriamente dita, mas não só, também proporcionam novas formas de sociabilidade, que não serão analisadas nesse trabalho. Alguns dos processos políticos, no entanto, existem antes e fora das TICs, outros são desenvolvidos nas e pelas TICs. Ambos têm em comum o envolvimento e a participação política da sociedade civil na reivindicação dos seus 
legitimidade de suas reivindicações através de protestos e denúncias no meio físico (protestos e manifestações de rua) ou através do uso de TICs, mais frequentemente no ambiente virtual, com petições e abaixo-assinados com aderência/“assinatura” virtual, como, por exemplo, os da organização não-governamental Avaaz, ${ }^{14}$ canais de denúncia jornalística, como o Mídia Ninja ${ }^{15}$ etc. Dessa meta-política defluem interferências na produção do direito fora do Estado, por mecanismos, instituições ou movimentos sociais nem sempre por ele reconhecidos.

A promulgação da lei complementar 135/2010, que alterou a lei complementar 64/90, a fim de estabelecer casos de inelegibilidade e cassação de mandato eletivo, conhecida como "Lei da Ficha Limpa", constitui um exemplo bastante ilustrativo. De iniciativa popular, a proposta contou com amplo envolvimento da sociedade civil (institucionalizada e não institucionalizada), que se mobilizou a fim de propor a lei ${ }^{16} \cdot{ }^{17}$

desejos bem como a pressão social para fazê-los atendidos e garantidos pelo Estado. Constituem uma nova possibilidade de incremento da participação política no que toca aspectos do desenvolvimento de políticas públicas ou mesmo na formulação de leis (SANTOS, 2016, p. 229).

${ }^{14}$ O Avaaz é uma organização da sociedade civil que surgiu em 2007 com o objetivo de promover campanhas, com coletas de assinaturas em âmbito internacional sobre diversos temas de interesse público. Está presente em mais de 190 países e possui mais de 40 milhões de membros cadastrados. É uma das novas ferramentas proporcionadas pelas TICs.

15 O grupo Mídia Ninja (Narrativas Independentes, Jornalismo e Ação) é uma rede descentralizada de mídia jornalística alternativa que atua através da internet, formulando diversos tipos de denúncias através de jornalismo também alternativo, com o uso de câmeras de celulares para a captação de imagens e confecção de matérias jornalísticas disponibilizadas na internet. $\mathrm{O}$ grupo atuou ativamente na cobertura dos protestos populares no Brasil, em 2013 e em 2015. Os primeiros (2013) suscitaram a possibilidade de um plebiscito sobre a reforma política, que seria convocado pela presidente Dilma Rousseff, que, no entanto, não ocorreu. Os segundos (2015) culminaram na pressão popular pela abertura do processo de impeachment da mesma, em 2016.

${ }^{16}$ A repercussão de sucessivos escândalos políticos tratados pela mídia e mais recentemente reverberados pelas TICs incentivou a sociedade civil a se organizar e ampliar a participação, exigindo respostas no campo político. A campanha da "Ficha Limpa" se colocou a partir dos avanços e conquistas de suas reivindicações. A ideia era promover um abaixo-assinado a fim de exigir novas posturas de candidatos a cargos eletivos.

17 Também a Lei 9.840/99, que alterou o Código Eleitoral a fim de criminalizar a captação ilícita de votos contou com a iniciativa popular capitaneada pelo movimento Comissão Brasileira Justiça e Paz, ligado à Conferência Nacional dos Bispos do Brasil (CNBB). O projeto "Combatendo a Corrupção Eleitoral" obteve 1,06 milhão de assinaturas até a apresentação da proposta à Câmara dos Deputados, em fevereiro de 1997. A Lei 11.124/2005 que dispõe sobre o Sistema Nacional de Habitação de Interesse Social (SNHIS), criadora do Fundo Nacional de Habitação de Interesse Social (FNHIS) e que instituiu o respectivo conselho gestor também é de iniciativa popular. O movimento social autodenominado "Movimento Popular por Moradia" encabeçou a coleta de mais de 1 milhão de assinaturas em 1992 e o projeto foi convertido em lei no ano de 2005. A Lei 8.930/94, que alterou a Lei 8.072/90, também conhecida como "Lei de Crimes Hediondos" a fim de inserir o homicídio qualificado no rol dos crimes hediondos contou com ampla participação popular. A mobilização popular ganhou notoriedade em razão da campanha nacional encabeçada pela autora de novelas Glória Perez após o homicídio de sua filha, a atriz Daniella Perez, em 1992. A campanha conseguiu 1,3 milhão de assinaturas e em 1994, o projeto foi convertido em lei.

CONPEDI LAW REVIEW | Braga - Portugal | v. 3 | n. 2 | p. 262 - 283 | JUL/DEZ. 2017 
Ensina Celso Fernandes Campilongo (2012, p. 28) que a interferência dos movimentos sociais no direito pode se dar de três modos: "contra", "pelo" e "após" o direito. "Contra o direito", significa o embate pela sua revogação, substituição ou por nova interpretação do direito vigente. Identifica-se um obstáculo construído pelo direito e procura-se removê-lo também através do direito. Não se trata de transgressão ou colidência com o direito, mas de sua modificação. "Pelo direito" representa a luta pelo reconhecimento e afirmação de direitos ainda não estabelecidos: conquista de novos direitos. "Após o direito" consiste na busca por eficácia: adoção de políticas, reorientação da jurisprudência em conformidade com os avanços legislativos, mudança de comportamentos.

Dessa perspectiva, os movimentos sociais quando atuam na discussão "contra", "pelo" e "após" o direito, potencializam a ação política, transferindo-a do parlamento para outros lócus de deliberação. Trata-se do reconhecimento das interferências do sistema social nos sistemas da política do direito. Com isso, a produção do direito se dá em instâncias extra-institucionais, fora do Estado e, por fim, acabam sendo por ele incorporadas como resposta às demandas sociais. $^{18}$

\subsection{Terceiro setor}

Apesar da indistinção entre os sistemas da economia, da política e do direito que a pósmodernidade engendra, as ciências sociais se esforçam em estabelecer contornos e limites. Com a superação do binômio Estado - sociedade civil em prol da separação entre Estado, mercado e sociedade civil, designando-se como primeiro setor, o Estado; o segundo, o mercado; e o terceiro, a sociedade civil (BOBBIO, 2011, p. 36), tem-se sob o manto do terceiro setor, todas as organizações privadas que desempenhem funções públicas ou que busquem objetivos que

\footnotetext{
${ }^{18}$ Exemplificativamente reporta-se à tramitação da PEC 37. A Proposta de Emenda à Constituição (PEC) no 37/2011 tinha como objetivo acrescentar o parágrafo 10 ao artigo 144 da Constituição Federal para definir a competência para a investigação criminal pelas polícias federal e civis dos Estados e do Distrito Federal, junto à Câmara dos Deputados. A celeuma se deu em razão da competência para a condução de procedimentos investigatórios criminais no âmbito do Ministério Público, conferida pela Resolução $\mathrm{n}^{\circ}$ 13/2006 do Conselho Nacional do Ministério Público (CNMP), que seria, em tese, suprimida. A PEC tramitava normalmente desde a sua proposição em 2011, obtendo pareceres favoráveis em todas as comissões legislativas nas quais foi submetida, por ampla maioria. Após a onda de protestos e manifestações populares de junho de 2013, a PEC foi rejeitada massivamente em 25 de junho de 2016 (não: 430, sim: 9, abstenções: 2, total 441) e arquivada em 28 de janeiro de 2015.
} 
beneficiem a sociedade como um todo, tais como associações, fundações e organizações não governamentais (ONGs).

Em que pese a separação entre Estado, mercado e sociedade civil é importante ressaltar que o desenvolvimento do terceiro setor é sustentado por mecanismos de interação e complementaridade, permitindo simbioses entre os três setores e comumente é apresentado como a busca por maior eficiência e eficácia na geração e uso de recursos humanos e materiais disponíveis (FERNANDES, 1997, p. 137).

O crescimento do terceiro setor, bem como a aproximação gradativa entre os três setores, evidenciando o desenvolvimento sinérgico entre o mercado, a sociedade civil e o Estado são muito evidentes na pós-modernidade. O declínio do Estado social e o ressurgimento do liberalismo, o avanço tecnológico e a intensificação do processo de globalização levaram o Estado a uma redefinição (OLIVEIRA, 2008, p. 15). Também as exigências democráticas reformataram o Estado, fazendo-o relegar progressivamente um papel imperativo e provedor e assumir uma postura mais consensual e relacional.

Assim, o Estado passa a concentrar apenas funções estratégicas, viabilizando um redesenho institucional e o desenvolvimento de capacidades gerenciais, rompendo com o intervencionismo e impulsionando a transformação da Administração Pública, que perde a sua configuração impositiva e burocratizada em favor de feições consensuais e gerenciais, substituindo o mecanismo clássico da coerção pelo da colaboração e assim produzindo um sistema de gestão pública (OLIVEIRA, 2008, p. 33).

No Brasil, as práticas filantrópicas, assistencialistas ou de solidariedade não são recentes. Podem ser observadas desde o período colonial, porém de forma precária e pouco articulada, em atividades geralmente vinculadas à Igreja (SOARES, 2008, p. 23). A novidade do terceiro setor brasileiro reside em sua formatação atual enquanto mecanismo de articulação e mobilização sociais.

O terceiro setor brasileiro começou a adquirir as feições atuais com a atuação dos movimentos sociais da década de 1970, que evoluíram para a articulação política das ONGs na década de 1980. Com a proliferação das instituições filantrópicas dedicadas à prestação de serviços públicos a fim de preencher as lacunas e deficiências do Estado, emergiram as 
organizações voltadas para a defesa de direitos, incentivadoras do seu exercício e da construção de novas demandas sociais, além de apoiarem o voluntariado e exigirem práticas empresariais socialmente responsáveis (CARDOSO, 1997, p. 9).

Sob essa perspectiva, a percepção de Gustavo Justino de Oliveira (2008) mostra-se relevante a fim de compreender o terceiro setor como conjunto de atividades voluntárias, desenvolvidas por organizações privadas não governamentais e sem ânimo de lucro (associações ou fundações) ${ }^{19}$, realizadas em prol da sociedade, independentemente dos demais setores (Estado e mercado), embora possa com eles firmar parcerias ${ }^{20}$ e deles possa receber investimentos (públicos e privados).

Importa pensar que o terceiro setor consubstancia uma nova forma de participação da sociedade civil, diferente da participação política tradicional que se dá através dos modelos de democracia representativa: é direta e não apenas tematiza demandas sociais, mas é propositiva em soluções e não tem a lucratividade como objetivo. Assevera Gustavo Justino de Oliveira (2011, p. 203) que não há que se falar em substituição ao Estado, mas em co-particação e coresponsabilidade $^{21}$.

A atuação da sociedade civil em atividades de caráter público através do terceiro setor revela a construção de uma nova forma de interação social e de produção do direito. A inscrição de espaços de participação da sociedade no arranjo constitucional das políticas sociais brasileiras apostou no potencial de novas institucionalidades, na transformação da cultura

\footnotetext{
${ }^{19}$ Ruth Cardoso (1997, p. 9) assevera que são vários os termos utilizados para caracterizar esse espaço que não é Estado nem mercado e cujas ações visam o interesse público: iniciativas sem fins lucrativos, filantrópicas, voluntárias. Pode ser que futuramente essa denominação seja inservível enquanto conceito unificador, mas o Brasil ainda se situa em uma etapa de afirmação de uma novidade, o que implica enfatizar sua autonomia e relevância. Trata-se de um espaço de participação e experimentação de novos modos de pensar e agir sobre a realidade social. Gustavo Justino de Oliveira (2008, p. 33) alerta, no entanto, que ainda que haja variações de nomenclatura para as organizações sociais do terceiro setor, o direito reconhece apenas duas: associações e fundações, que são aquelas que encontram previsão legal junto ao Código Civil brasileiro.

${ }^{20}$ As parcerias entre a sociedade civil (terceiro setor) e o Estado foram regulamentadas pela Lei 13.019/2014, que fortalece a participação social por meio da previsão do Procedimento de Manifestação de Interesse Social - PMIS (artigos 18 a 21) e o controle social por meio da previsão de regras de publicidade e acesso às informações (artigos 9, 10 e 11), de modo a conferir transparência ao manuseio da verba pública, como reconhecer a necessidade de capacitação dos gestores públicos, conselheiros e sociedade civil.

${ }^{21} \mathrm{O}$ ressurgimento da sociedade civil brasileira na pós-modernidade é, em grande medida, analisada sob a perspectiva contra-hegemônica, o que, entretanto, requer certa cautela, haja vista que o excesso de absenteísmo estatal pode significar a progressiva subtração da prestação de direitos sociais pelo Estado, relegando-a ao terceiro setor - argumento rebatido pelas teorias provenientes da chamada "nova Administração Pública", calcadas nas ideias de subsidiariedade e de complementaridade da atividade estatal, que, porém, não constituem objeto do presente estudo.
}

CONPEDI LAW REVIEW | Braga - Portugal | v. 3 | n. 2 | p. 262 - 283 | JUL/DEZ. 2017 
política com a introdução de novos sujeitos na atuação do Estado. Mas não só. A produção do direito, bem assim, a soberania estatal, foram também profundamente afetadas.

\subsection{Política nacional de participação social}

O Decreto 8.243/2014, que institui a Política Nacional de Participação Social (PNPS) no Brasil entende por sociedade civil, o cidadão, os coletivos, os movimentos sociais institucionalizados ou não institucionalizados, suas redes e suas organizações (artigo $\left.2^{\circ}, \mathrm{I}\right)$.

A PNPS constitui uma política pública do Estado brasileiro voltada para a ampliação dos canais de participação da sociedade civil. Com a promulgação da Constituição Federal de 1988 foram instituídos diversos mecanismos de participação social, para além da representação (plebiscitos, na forma do artigo 14, I; referendos, artigo 14, II; e, iniciativas populares, artigo 14, III). Além disso, há outros mecanismos (artigos $27, \S 4^{\circ}$ e 29, XII) em que se observa a participação social, abrindo caminho a tantos outros que logo foram incorporados ao direito, como conselhos, conferências, ouvidorias, processos de participação no ciclo de planejamento e orçamento públicos, audiências e consultas públicas, mesas de diálogo e negociação e outros.

A exigência constitucional de participação política da sociedade civil não se limita ao poder executivo, nem à formulação de políticas públicas. Abrange o poder legislativo (artigo $61, \S 2^{\circ}$ da Constituição Federal) em formas de participação em que atores sociais participam da atividade legiferante propriamente dita, e, em relação às políticas públicas, no tocante ao conjunto normativo necessário para que se concretizem. ${ }^{22}$

\footnotetext{
${ }^{22}$ Também o poder judiciário já passa a recorrer às audiências públicas para a oitiva da sociedade civil no julgamento de ações cujos temas sub judice tenham repercussão geral e interesse público. Constituem exemplos de audiências públicas convocadas pelo Supremo Tribunal Federal no âmbito da ação direita de inconstitucionalidade - ADI 3510, sobre pesquisas com células tronco, realizada em 20 de abril de 2007; arguição de descumprimento de preceito fundamental - ADPF 101, em face de decisões judiciais que autorizavam a importação de pneus usados, realizada em 27 de junho de 2008; arguição de descumprimento de preceito fundamental - ADPF 54, sobre a interrupção de gravidez de fetos anencéfalos, realizada em 4 de setembro de 2008; o debate acerca da judicialização da saúde, realizado nos dias 27, 28 e 29 de abril de 2009 e em 4, 5 e 6 de maio de 2009; arguição de descumprimento de preceito fundamental - ADPF 186 e Recurso Extraordinário - Rext 597285 sobre as políticas afirmativas de acesso à universidades públicas (também conhecido por "sistema de cotas"), realizada em 3 de março de 2010; ação direita de inconstitucionalidade - ADI 4439, sobre a inclusão do ensino religioso na grade curricular as escolas públicas, realizada em 15 de junho de 2015 dentre outras, todas contando com ampla participação social. Essas audiências públicas, muito embora não façam parte da política nacional de participação social, demonstram que o poder judiciário encontra-se afinado a essa tendência.
} 
A ideia de participação social cresceu exponencialmente no Brasil, a exemplo dos conselhos de políticas e dos orçamentos participativos. ${ }^{23}$ Os conselhos de políticas públicas são resultado das leis específicas que regulamentam a Constituição Federal, no que tange à saúde, assistência social, criança e adolescente e políticas urbanas.

Assim, a PNPS busca institucionalizar a participação da sociedade civil na esfera governamental, consolidando os mecanismos de participação social já existentes. Para tanto, explicita as diretrizes ${ }^{24}$ e objetivos ${ }^{25}$ gerais da participação social no âmbito governamental.

A PNPS busca consolidar a participação como um método de governo. Além de contar com a participação da sociedade civil institucionalizada, reconhece a parcela da sociedade civil não institucionalizada, como movimentos sociais autônomos e informais, possibilitando que também esses possam participar de debates. Além disso, o decreto 8.243/2014 institucionaliza novas formas de participação social por meio de TICs, em especial a internet, a fim de promover o diálogo entre a administração pública federal e a sociedade civil

A participação social afirma o objetivo de ausculta política da sociedade civil, salientando seu papel na promoção e na participação efetiva do cidadão nos processos de planejamento e decisão social, pois a democracia implica no que Arango (2002, p. 130)

\footnotetext{
${ }^{23}$ A principal referência de orçamento participativo é a experiência de Porto Alegre, a partir da década de 1990, seguida de Belo Horizonte, São Paulo e Recife.

${ }^{24}$ A PNPS no artigo $3^{\circ}$ fixa como diretrizes: I - o reconhecimento da participação social como direito do cidadão e expressão de sua autonomia; II - complementaridade, transversalidade e integração entre mecanismos e instâncias da democracia representativa, participativa e direta; III - solidariedade, cooperação e respeito à diversidade de etnia, raça, cultura, geração, origem, sexo, orientação sexual, religião e condição social, econômica ou de deficiência, para a construção de valores de cidadania e de inclusão social; IV - direito à informação, à transparência e ao controle social nas ações públicas, com uso de linguagem simples e objetiva, consideradas as características e o idioma da população a que se dirige; V - valorização da educação para a cidadania ativa; VI autonomia, livre funcionamento e independência das organizações da sociedade civil; e VII - ampliação dos mecanismos de controle social

${ }^{25}$ No artigo $4^{\circ}$, são definidos os seguintes objetivos: I - consolidar a participação social como método de governo; II - promover a articulação das instâncias e dos mecanismos de participação social; III - aprimorar a relação do governo federal com a sociedade civil, respeitando a autonomia das partes; IV - promover e consolidar a adoção de mecanismos de participação social nas políticas e programas de governo federal; V - desenvolver mecanismos de participação social nas etapas do ciclo de planejamento e orçamento; VI - incentivar o uso e o desenvolvimento de metodologias que incorporem múltiplas formas de expressão e linguagens de participação social, por meio da internet, com a adoção de tecnologias livres de comunicação e informação, especialmente, softwares e aplicações, tais como códigos fonte livres e auditáveis, ou os disponíveis no Portal do Software Público Brasileiro; VII desenvolver mecanismos de participação social acessíveis aos grupos sociais historicamente excluídos e aos vulneráveis; VIII - incentivar e promover ações e programas de apoio institucional, formação e qualificação em participação social para agentes públicos e sociedade civil; e IX - incentivar a participação social nos entes federados.
}

CONPEDI LAW REVIEW | Braga - Portugal | v. 3 | n. 2 | p. 262 - 283 | JUL/DEZ. 2017 
descreve como "processo de criação, circulação e distribuição igualitária do bem social. Ou melhor, é justamente a institucionalização da participação igualitária dos cidadãos no processo de decisão sobre a cidade, sobre o seu país. Sobre os public goods, diriam os anglosaxões, sobre a polis, diriam os gregos. Quem faz parte desse processo decisório? Todos".

Muito se discute se PNPS sinalizaria mudanças no sistema político, de forma a ferir a representação política, ínsita na Constituição Federal, ao instituir uma nova fonte de poder proveniente da participação direta, sobretudo na produção normativa. Com Celso Fernandes Campilongo (1988, p. 49) é possível concluir que sendo as instituições representativas os mecanismos do sistema político mais vinculados à produção de leis, é natural que a participação direta tenha reflexos no direito. No contexto de transformações do Estado na pós-modernidade, a interpenetração cada vez maior entre Estado, mercado e sociedade civil revela que essa tríade não é antitética e tampouco contraposta. É possível perceber que a política e o direito não se reduzem à política e ao direito estatais. Isso implica no reconhecimento de que a representação política estatal não tem nem o monopólio da representação social, nem a exclusividade da produção normativa: existe uma pluralidade de pólos de produção do direito e, ipso facto, de lugares de exercício das atividades representativas. Isso perfaz um cenário em que o monopólio do Estado na produção do direito e, portanto, a soberania estatal, resta profundamente afetada.

\section{Considerações finais}

A doutrina da soberania compreende diversas acepções. Dentre as teorias jurídicas, destaca-se a teoria da "soberania estatal", segundo a qual a soberania incumbe ao Estado, enquanto ente dotado de personalidade jurídica. Nessa perspectiva, há convergência da produção normativa no Estado, que constitui o fundamento do Estado moderno. A partir dessa construção teórica, o Estado se fortalece enquanto centralidade e exclusividade, passando a concentrar o monopólio da produção do direito.

Com a pós-modernidade, todavia, essa ideia de soberania começa a enfraquecer, assim como a centralidade estatal, que vai paulatinamente perdendo espaço e abrindo caminho para construções teóricas mais receptivas e sensíveis ao contexto atual, entrecortado pela complexidade e heterogeneidade. O Estado perde o seu monopólio normativo e a soberania estatal passa a ser questionada.

CONPEDI LAW REVIEW | Braga - Portugal | v. 3 | n. 2 | p. 262 - 283 | JUL/DEZ. 2017 
É certo que modernidade e pós-modernidade não significam apenas períodos históricos. São formas de conceber, por sistemas de pensamento, a dimensão dos fatos e (re)configurações que se originam em seus tempos. Também não se restringem à filosofia, à sociologia, à economia ou ao direito, mas a um cabedal reflexivo que perpassa toda a vida contemporânea, das teorizações, à arte, à literatura, à arquitetura etc.

A noção moderna de norma jurídica envolve a ideia de direito posto pelo Estado. Disso defluem dois postulados: de que o Estado monopoliza a produção do direito e o parlamento detém a exclusividade de representação. Na pós-modernidade, no entanto, esses dois postulados são concorrentes: formas paralelas de normatividade e de participação política contestam esses monopólios.

Nesse contexto, a sociedade civil emerge como novo elemento a compor o direito na pós-modernidade, evidenciando a contraposição entre o modelo rígido e fixo da concepção tradicional de Estado e de soberania para a indefinição, a provisoriedade e a ruptura que a pósmodernidade convola.

A mitigação da exclusividade do Estado na produção do direito na pós-modernidade e, portanto, da soberania estatal através da atuação da sociedade civil a compor o direito e, assim, a própria soberania, significa pensar uma soberania estatal reformatada por novos paradigmas e novos sujeitos, alterando profundamente os postulados construídos na modernidade, até então considerados invioláveis, segundo a ordem de Westphalia.

\section{Referências bibliográficas}

ALVES, A. C. A função ideológica do direito na sociedade moderna. In: CLÈVE, C. M.; BARROSO, L. R. Doutrinas essenciais de direito constitucional. São Paulo: RT, 2011. v. 2.

ARANGO, M. Philantropy in Mexico. Boston: Harvard Review of Latin America, 2002.

BAUMAN, Z. Modernidade líquida. Rio de Janeiro: Zahar, 2000.

BECK, U. Sociedade de risco: rumo a uma outra modernidade. São Paulo: Editora 34, 2010.

BITTAR, E. C. B. O direito na pós-modernidade (e reflexões frankfurtianas). 2 ed. Rio de Janeiro: Forense, 2009.

BOBBIO, N. Estado, governo, sociedade: para uma teoria geral da política. São Paulo: Paz e Terra, 2011.

BODIN, J. Les six livres de la République. Paris: Fayard, 1986.

BULOS, U. L. Curso de direito constitucional. 3 ed. São Paulo: Saraiva, 2009. 
CAMPILONGO, C. F. Direito na sociedade complexa. São Paulo: Max Limonad, 2000.

CAMPILONGO, C. F. Interpretação do direito e movimentos sociais. Rio de Janeiro: Elsevier, 2012.

CAMPILONGO, C. F. Representação política. São Paulo: Ática, 1988.

CARDOSO, R. O fortalecimento da sociedade civil. In: IOSCHPE, E. B. $3^{o}$ setor: desenvolvimento social sustentado. São Paulo: GIFE, 1997.

CARVALHO, J. M. Cidadania no Brasil: o longo caminho. 3 ed. Rio de Janeiro: Civilização Brasileira, 2002.

CASELlA, P. B. Fundamentos do direito internacional pós-moderno. São Paulo: Quartier Latin, 2008.

DELLA PORTA, D. Democracy in social moviments. New York: Palgrave MacMillan, 2009.

FARIA, José Eduardo. Sociologia jurídica: direito e conjuntura. Série GVLaw. São Paulo: Saraiva, 2011.

FERNANDES, R. C. O que é terceiro setor? In: IOSCHPE, E. B. $3^{o}$ setor: desenvolvimento social sustentado. São Paulo: GIFE, 1997.

FOUCAULT, M. Microfísica do poder. Rio de Janeiro: Graal, 1979.

GIDDENS, A. As conseqüências da modernidade. Rio de Janeiro: Zahar, 2002.

HABERMAS, J. A constelação pós-nacional: ensaios políticos. São Paulo: Littera Mundi, 2001.

HARVEY, D. Condição pós-moderna: uma pesquisa sobre as origens da mudança cultural. São Paulo: Loyola, 2008.

HOBBES, T. Leviatã ou matéria: forma e poder de um estado eclesiástico e civil. São Paulo: Abril, 1984.

LEWANDOWSKI, E. R. Globalização, regionalização e soberania. São Paulo: Juarez de Oliveira, 2004.

LIPOVETSKY, G. Pós-modernidade e hipermodernidade. In: FORBES, J.; REALE JÚNIOR, M.; FERRAZ JÚNIOR, T. S. A invenção do futuro. Barueri: Manole, 2005.

LUHMANN, N. Sociologia del riesgo. Guadalajara: Walter de GrurterCo., 1992.

MARSHALL, T. H. Cidadania, classe social e status. Rio de Janeiro: Zahar, 1963.

McCANN, M. Law and social movements. Washington: Ashgate Publishing, 2006.

MELUCCI, A. A invenção do presente: movimentos sociais nas sociedades complexas. Petrópolis: Vozes, 2001.

MIRANDA, J. Teoria do Estado e da constituição. 4 ed. Rio de Janeiro: Forense, 2015.

MONTESQUIEU, C. L. O espírito das leis. São Paulo: Martins Fontes, 2005.

OLIVEIRA, G. J. Direito do terceiro setor. Belo Horizonte: Forum, 2008. 
OLIVEIRA, G. J. Terceiro setor: desenvolvimento social sustentável. In: CARDOZO, J. E. M.; QUEIROZ, J. E. L; SANTOS, M. W. B. Direito administrativo econômico. São Paulo: Atlas, 2011.

OTTMANN, G. Movimentos sociais urbanos e democracia no Brasil: uma abordagem cognitiva. Novos Estudos CEBRAP, São Paulo, n. 41. p. , 1995.

PAUPÉRIO, M. O conceito polêmico de soberania. Rio de Janeiro: Forense, 1955.

RAJAGOPAL, B. International law below: development, social movements and third world resistance. Cambridge: Cambridge University Press, 2003.

RANIERI, N. Teoria do Estado: do Estado de direito ao Estado democrático de direito. Barueri: Manole, 2013.

REALE, M. Teoria do direito e do Estado. 4 ed. São Paulo: Saraiva, 1984.

ROUSSEAU, Jean Jacques. Do contrato social. São Paulo: Martin Claret, 2007.

SANTOS, B. de S. Pela mão de Alice: o social e o político na pós-modernidade. 10 ed. São Paulo: Cortez, 2005.

SANTOS, M. B. Lei da ficha limpa: entre a sociedade civil e arranjos estatais. In: MESQUITA, N. C. Brasil: 25 anos de democracia, participação, sociedade civil e cultura política. Rio de Janeiro: Fundação Adenauer Stifung/NUPPs-USP, 2016.

SIEYÈS, E. J. O que é o terceiro Estado? Rio de Janeiro: Liber Juris, 1988.

SOARES, G. de O. O terceiro setor e o transindividualismo: proposta de uma teoria geral. Dissertação de Mestrado. São Paulo: Pontifícia Universidade Católica de São Paulo, 2008. 